the observations extend over nearly a month, and M. Fayet has made another research regarding this comet's orbit, obtaining the following set of elements as his result :-

$$
\begin{aligned}
& \mathrm{T}=1905 \mathrm{Jan} .1665370 \text { (M.T. Paris) } \\
& \mathrm{B}_{8}=76^{\circ} 4 \mathrm{I}^{\prime} 34^{\prime \prime} \cdot 49 \\
& i=30^{\circ} 3 \mathrm{I}^{\prime} 5^{8^{\prime \prime}} 75 \text { - } 1905^{\circ} \mathrm{O} \\
& \left.\infty=352^{\circ} 13^{\prime} 58^{\prime \prime} \cdot 98\right) \\
& \log q=0.145^{175} \\
& \log e=9.792206 \\
& \mu=503^{\prime \prime} \cdot 932
\end{aligned}
$$

These elements give a close agreement with the places determined by independent observations, and indicate that Borrelly's 1904 comet is, really, of the short-period type, completing its orbital revolution in about seven years, instead of six years as given by the previous elements (Comptes rendus, No. 5, 1905).

The Sun's Rotation.-During the years 1899 , 1900, and 1901 Prof. N. C. Dunér made a further series of observations of the rotation velocity of the sun at different heliocentric latitudes. Combining the results with those obtained by him during a similar research prosecuted in the years $1887-1889$, and now corrected, he found the values given in the following table:-

$\begin{array}{ccccccccc}\phi & & \begin{array}{c}v \\ \mathrm{~km} .\end{array} & & n & & \xi \cos \phi & & \xi \\ 0.4 & \ldots & +2.08 & \ldots & 183 & \ldots & 14.770 & \ldots & 14.77 \\ 150 & \ldots & +1.97 & \ldots & 180 & \ldots & 13.989 & \ldots & 14.48 \\ 30.1 & \ldots & +1.70 & \ldots & 184 & \ldots & 12.072 & \ldots & 13.95 \\ 450 & \ldots & +1.27 & \ldots & 181 & \ldots & 9.018 & \ldots & 12.75 \\ 60.0 & \ldots & +0.81 & \ldots & 183 & \ldots & 5.752 & \ldots & 11.50 \\ 750 & \ldots & +0.39 & \ldots & 184 & \ldots & 2.769 & \ldots & 10.70\end{array}$

wherein $\phi=$ the heliocentric latitude, $v=$ the rotational velocity of the sun's edge, $n=$ the number of observations, and $\xi=$ the daily rotation angle (Astronomische Nachvichten, No. 3994).

Secondary Shadow on Saturn's Rings.-During a series of observations of Saturn made at Aosta (Italy) in October, November, and December, 1904, Signors M. Amann and $\mathrm{Cl}$. Rozet observed a secondary shadow, other than that of the planet, projected on to the illuminated surface of the rings. First seen on October 20 , this shadow was thinner and much less accentuated than that of the planet, whilst its curvature was in the opposite sense to that of the latter body. From October 20 to November ${ }^{15}$, despite the fact that numerous opportunities of observing it occurred, the shadow was not seen, but from the latter date until the end of December it was shown on twenty-six drawings of the system. On seven drawings made between December 22 and 27 , the shadow appeared bifurcated where it traversed the inner ring, and on November 28 and 29 a third line of shadow, narrower and feebler than the preceding and much further from the planet, was seen (Comptes rendus, No. 5, 1905).

Observations of the Zodiacal Light.-During a sojourn on the summit of Mont Blanc on September 2 I and 22 , I904, M. A. Hansky made a number of observations of the Zodiacal Light, and found that its form was that of a spherical triangle having its apex near to the ecliptic. At 3 h. 4om. (M.T. Paris) the altitude of the apex was $52^{\circ}$, the length of the triangle, reckoned from the centre of the sun, was $80^{\circ}$, and its breadth was, at the horizon, $25^{\circ}$, and in the plane of the sun's axis $30^{\circ}$. The latitude of the apex was $+2^{\circ}$, and three zones were distinguishable in the light. The first of these had the form of a spherical triangle and was very feeble, the second was more parabolic, whilst the form of the third was a parabola.

In his paper, published in the Comptes rendus (No. 6, 1905), M. Hansky indicates the points of resemblance between this phenomenon and the corona, and makes a number of speculations as to the true nature of the light. $\mathrm{He}$ concludes by saying that he believes it to be an electrical phenomenon of the same type as the corona, and that it is, probably, simply a prolongation of the core al streamers.

Permanent Numbers for the Minor Planets discovered DURING 1904.--In No. 3994 of the Astronomische Nachrichten, the permanent numbers allotted to the minor planets discovered during 1904 are given. The list con- tains the numbers $5^{22}$ to 548 , inclusive, thereby showing the number discovered during last year to be twenty-seven. The provisional designation, the name of the discoverer, the date of discovery, and the authority for the orbit are also given for each planet. A number of notes explain the absence, for various reasons, of several bodies, to which provisional designations were allotted, from the final list.

\section{STUDIES IN EUGENICS.}

A T a meeting of the Sociological Society on February 14 $\mathrm{A}_{\mathrm{Mr}}^{\mathrm{T}}$ a Francis Galton communicated two papers :(1) restrictions in marriage, and (2) studies in national eugenics.

In the first paper he remarked that marriage, as one of the social agencies that influenced the racial qualities of future generations, came within the purview of eugenics. It belonged to the practical policy arising out of eugenic science, to promote such choice in marriage as should tend to the reproduction of the higher types of individual. Anthropological investigation had shown marriage to be one of the most modifiable of social institutions. Hence the assumption was warrantable that with the gradual incorporation of eugenic conceptions in the social ideal, there would proceed a concomitant change in the customs and conventions affecting marriage. The paper then proceeded to illustrate by actual examples the modifiability of marriage customs. In one or other of its many forms polygamy was now permitted-by religion, customs and law-to at least one-half of the population of the world, though its practice might be restricted, on account of cost, domestic peace, and the insufficiency of females. In Christian nations the prohibition of polygamy, under severe penalties, by civil and ecclesiastical law had been due, not to any natural instinct against the practice, but to consideration of social well-being. Hence it might be inferred that equally strict limitations of freedom of marriage might, under the pressure of worthy motives, be hereafter enacted for eugenic and other purposes. Endogamy, or the custom of marrying exclusively within one's own tribe or caste, had been sanctioned by religion and enforced by law in all parts of the world, but chiefly in long-settled nations, where there was wealth to bequeath and where neighbouring communities professed different creeds. Endogamous systems of marriage rested on customs determined by a certain religious view of family property and family descent. Eugenics dealt with what was more valuable than money or lands, namely, with natural inheritance of high character, capable brains, fine physique and vigour, in short, with all that was most desirable for a family to possess. It aimed at the evolution and preservation of high races, and it well deserved to be strictly enforced. In every society there existed conventional restrictions of the nature of "taboo," though not necessarily called by that name. If non-eugenic unions were prohibited by such taboos, none would take place. Marriage selection was very largely conditioned by motives based on religious and social convention. Persons who were born under the various marriage systems lived under such rules without any objection. They were unconscious of their restriction.

Under the heading "Studies in National Eugenics," Mr. Galton communicated what he described as "an un authorised programme" of what he conceived to be the duties of the Francis Galton research fellowship in national eugenics. The topics to be considered he classified under the following headings:-(1) Estimation of the average quality of the offspring of married couples from their personal and ancestral data. This included questions of fertility, and the determination of the probable error of the estimate according to the data employed. (2) Effects of action by the State and by public institutions. (3) Other influences that further or restrain particular classes of marriage. (4) Heredity. The facts, after being collected, should be discussed, for improving our knowledge of the laws both of actuarial and of physiological heredity, the recent methods of advanced statistics being of course used. (5) Bibliographical compilations. (6) Extension of eugenic studies by wider cooperation. (7) Certificates. With regard to the last named, he said that in some future time, dependent on circumstances, he looked forward to a suit-

NO. 1843 , VOL. 7 I] 
able authority issuing eugenic certificates to candidates for them. They would imply more than an average share of the several qualities of at least goodness of constitution, of physique, and of mental capacity.

The discussion on the papers was opened by Dr. Haddon, who said Mr. Galton sought to establish a science of eugenics, he took it, because the postulates of eugenics were an inevitable corollary from the general doctrine of organic evolution-in the building up of which $\mathrm{Mr}$. Galton had played a notable part. The evolution of the species having reached a self-conscious stage in man, it followed of necessity that increasingly rational and coordinated attempts should be made to guide ind direct the evolutionary process towards definable and verifiable ideals. It was, as he understood it, the aim of eugenic studies to ascertain the means available for this rational guidance of human evolution, and the defining of the ideals towards which it should be directed. There was ample warrant in anthropological data for the assumption that in the development of marriage customs there was a tendency towards adaptation to higher social purposes.

Dr. F. W. Mott said there were two general ways towards the rational improvement of the stock:-(i) by checking the reproduction of the unfit, and (2) by encouraging the reproduction of the fit. For the former purpose the readiest means would be the segregation of defective children while quite young, and the curtailment of their social privileges as they grew to maturity. As regards means towards the encouragement of fertility in the higher types, he suggested as an initial tentative in practical measures a further development of the present system of marriage registration. Why, for instance, should not medical as well as legal certificates of marriage be procurable at registry offices? The former would be of the nature of a bill of health, certifying that the contracting parties reached a certain standard of hygienic requirement. Such certificates would of course be voluntary, but since they would be valuable not only to their possessors but also to their children, they would tend to come into general usage. In any case he considered it a matter of national importance that Mr. Galton's conception of eugenics should be most seriously considered. The first desideratum was to get it accepted as a legitimate and hopeful study.

Mr. Ernest Crawley said Mr. Galton's paper showed how anthropological studies could be made fruitful in practical politics. Sociology should be founding its science of eugenics upon anthropology, psychology, and physiology. $\mathrm{He}$ hoped that while chiefly considering the normal individual it would not forget the special claims of those abnormal persons whom we call geniuses. In a well ordered State they should be considered before the degenerate and the diseased. As regards marriage customs he took it as an assured generalisation of anthropological science that there are two permanent polar tendencies in human nature, first against unions in the same home, and secondly against too promiscuous marriage. Many customs assumed by early anthropologists as normal types were he believed, merc sports-such as group-marriage, and marriage of brother and sister. Polygamy he believed to be an example of a certain tendency in man to confuse sexual (i.e. organic), with matrimonial (i.e. social) concerns. They must beware of this confusion, and therefore be on their guard against its possible effects in studying eugenics. Mr. Galton's suggestion that religion was called upon to play a part in the development of eugenics he considered to be a sound deduction from history and anthropology. In the sanctification of marriage, religion had one of its earliest and greatest functions; and as primitive religion, in this as in other respects, was based upon the best knowledge of primitive times (i.e. upon primitive science), so the most developed form of religion should be illuminated by the most advanced form of knowledge (i.e. by contemporary science).

Dr. E. Westermarck said he entirely agreed with Mr. Galton's contention that restrictions in marriage as they existed in the simpler social formations, so they might be further modified and developed for eugenic purposes amongst the most highly civiliscd peoples. The germ of eugenic intentions was well seen amongst savage and barbarian peoples in those customs which imposed a test NO. I 843 , voI 71$]$ of fitness on the husband before marriage. In Kaffir tribes, for instance, a man may not marry until he has demonstrated his strength and courage and competence in the chase by killing a rhinoceros. In the Malay Archipelago there are peoples where the marriage test consists in the collection of a number of skulls from hostile tribes. Among the Arabs of Upper Egypt, the young aspirant to marriage must evidence his courage and self-control by suffering-with smiling countenance-a severe ordeal of whipping by the relatives of the bride. He considered that on this question of marriage, whereby the individual was brought into both organic and social relation with the species, moral teachers had before them one of the greatest of tasks, in inculcating a keener sense of foresight in the individual. There was perhaps hardly any other point in which the moral consciousness of civilised men stood in greater need of intellectual training.

As contributions to the discussion, a considerable number of written communications were received, from the following amongst others:-Dr. Havelock Ellis, Mr. A. H. Huth, Dr. Max Nordau, and Profs. Yves Delage, J. G. McKendrick, Posada, Sergi, Steinmetz, Tonnies, and Weismann. The last named raised the question whether, when a hereditary disease like tuberculosis has made its appearance in a family, it is afterwards possible for it to be banished entirely from this or that branch of the family, or whether, on the contrary, the progeny of those members who appear healthy must not sooner or later produce a tuberculous progeny. He himself considered that a tainted stock might produce a branch entirely free from that specific disease.

Mr. Galton, in the course of his reply, said it gave him satisfaction to find that no one amongst his critics had impugned the conclusion which his memoir on "Restrictions in Marriage" was written to justify.

\section{THE ABSORPTION OF LIGHT BY THE ATMOSPHERE.}

THE great attention that has been paid during the last few years to the subject of photometry has brought into prominence the problem of the amount of light absorbed by the atmosphere. At the same time, the improvement that has taken place in the instrumental means, which renders possible the detection of minute changes in lustre, has required the use of accurate corrections by which the effect of the earth's atmosphere can be eliminated from the observations. The corrections which have been applied to photometric measures have been based generally on empirical or interpolation methods rather than on a strictiy physical basis. There are several reasons which have contributed to this unsatisfactory condition of the problem. The difficulty of computing the length of the path of the ray of light in its passage through our atmosphere, the want of homogeneity in the constitution of the atmosphere itself, our ignorance of the law of the temperature gradient at considerable heights above the surface, and of the distribution of water and dust particles near the surface, have all complicated a subject the theory of which under ideal limiting conditions may not be very difficult. Bouguer left a very satisfactory theory, based, however, on the assumption that the path of the ray was rectilinear. Laplace attacked the subject from the side of the theory of refraction, but practically did not much advance it. From that time onward, the question has rather been left in the hands of observers, who have been content to make their observations homogeneous by the employment of an interpolation formula, based on the results of their actual practice.

Dr. A. Bemporod thinks that the time has come for the discussion of a physical theory of the extinction of light in the atmosphere, and certainly his pamphlet bearing this title is a most welcome contribution to this subject. It may be that in some sense it is a premature effort. That is to say, that the data for a complete solution of the problem do not exist. The series of observations which are now being conducted by means of kites and balloons, and which have for their object the examination of the different

1 "Zur Theorie der Extinktion des Lichtes in der Erdatmosphäre." By Dr. A. Bemporod. Pp. 78. (Mitteilungen cier Grossh. Sternwarte zu Heidelberg ) 